\title{
Dietetics and Nutrition Students Response to Grocery Store Tour Training Program
}

\author{
Elizabeth D Hilliard ${ }^{1}$, Ardith Brunt ${ }^{1}$, Christa Froelich ${ }^{1}$, Mari Borr ${ }^{1}$ \\ ${ }^{1}$ North Dakota State University, USA \\ Correspondence: Elizabeth D Hilliard, North Dakota State University, USA.
}

Received: January 10, 2018

Accepted: January 30, 2018 Online Published: February 15, 2018

doi:10.11114/jets.v6i3.2921

URL: https://doi.org/10.11114/jets.v6i3.2921

\begin{abstract}
Retail dietetics is a growing field, however, there is very little research available on effective teaching strategies for preparing students to enter this part of the profession. This paper is the second paper to report on the results of produce -focused grocery store tour training program. This paper focuses on the trained students' perception of the program's effectiveness. Twenty-five dietetics and nutrition students were trained in providing produce - based grocery store tours, and then gave store tours to other college students. Students completed a pre - and post - training survey rating their confidence in providing this type of education and on their intention to do so as part of their career. Students rated their confidence level in giving produce - based grocery store tours significantly higher after the training than before ( $\mathrm{p}<$ 0.05). However, the training program did not significantly increase the student's intention in pursuing a career that included giving grocery store tours. The results of this study indicate that a practical training program in giving store tours may increase students' comfort level with doing so.
\end{abstract}

Keywords: college students, nutrition, educational training, eating behavior, consumer

\section{Introduction}

\subsection{The Problem}

The demand for Registered Dietitian/Nutritionists (RDN's) in grocery stores is increasing (Produce for Better Health Foundation, n.d.). Retail dietetics is a rapidly growing field with 95\% of stores surveyed in 2015 as part of a Food Marketing Research Institute study reporting that they employed RDN's at a local, regional, or corporate office (Food Marketing Institute, 2015). However, until recently, very little training on grocery store tours has been available to dietetics and nutrition students. In 2014, a pilot store tour training program was conducted at a university in combination with a local grocer (Produce for Better Health Foundation, n.d.). This pilot program lead to a partnership between the Produce for Better Health Foundation (PBH) and retail dietitians, and eventually to the development of a formal grocery store tour training program for dietetics and nutrition students (Thompson, Silver, Pivonka, Gutschall, \& McAnulty, 2015). The program was designed to 'increase dietetics and nutrition students' proficiency in giving produce-based grocery store tours, increase college student tourists exposure to various types of produce, and develop partnerships with grocers" (Hilliard, Brunt, Stangl, \& Borr, 2016). To encourage more universities to adopt the training program, PBH also developed a grant program to provide any needed funding. As of February 2017, PBH has funded 44 university grocery store tour training programs (K. Stevens, personal communication, February 27, 2017).

\subsection{Importance of the Problem}

While many universities have received the PBH funding, little research has been published on the results. In 2015, Thompson, Silver, Pivonka, Gutschall, \& McAnulty published a summary of the initial results of the training program. From the results of a post-tour survey, they found that $69 \%$ of the tour recipients indicated an intention to eat more produce, and many tour recipients were able to recall key messages presented on the tour (Thompson et al., 2015). Another study by Hilliard, Brunt, Stangl, \& Borr (2016) reported results from a PBH funded program at a Midwestern university. They found $76 \%$ of tour recipients stated the tour would make a difference in their fruit and vegetable intake (Hilliard et al., 2016). Additionally, Hilliard et al. (2016), examined the demographics of who volunteered to receive a store tour and found that most of the volunteers were female, had a healthy body mass index (BMI) based on self-report, and felt they were healthy eaters (Hilliard et al., 2016). 


\subsection{Relevant Scholarship}

Overall, there is very little research on the impact of grocery store tours on consumer behavior related to produce intake. A systematic review of literature by Nikolaus, Muzaffar, \& Nickols - Richardson (2016) found that out of 8 articles on grocery stores meeting selection criteria, there was evidence of short term knowledge and behavior changes $(<3$ mo), but no indication of longer term outcomes. Additionally, there was little consensus on what elements are common among tours (Nikolaus, Muzaffar, \& Nickols-Richardson, 2016). Other studies have also provided evidence of short term intake changes, and intention to increase variety of foods consumed especially produce (Milliron, Woolf, \& Appelhans, 2012; Thompson et al., 2015), low fat dairy and whole grains (Crawford \& Kalina, 1993). Research on store tours has focused on populations from college students (Hilliard et al., 2016; Thompson et al., 2015) to those with cardiovascular disease (Baic \& Thompson, 2007).

\subsection{Purpose of the Study}

There is still a need for more research on the impact of grocery store tours on behavior change and what are considered best practices for tours. Additionally, there is almost no literature available on the impact of the store tour training programs with regards to the dietetics and nutrition students who were trained to give the tours. This study is the second report on data collected from a training program conducted at a Midwestern university in 2015 (Hilliard et al., 2016). The first report examined the characteristics of those volunteering to receive a store tour from the trained dietetics and nutrition students. This second report examines whether the trainees' experienced a change in their level of comfort educating the public on produce and would consider grocery store dietetics as a career.

\section{Method}

The methods of this study were described in detail in a previous manuscript (Hilliard et al., 2016). A brief description is listed here.

\subsection{Background on the Training Program}

This study was approved by the University's Institutional Review Board (HE16062). In the fall of 2015, dietetics and nutrition students who were enrolled in a community nutrition class were trained in giving grocery store tours using the Produce for Better Health Grocery Store Tour Training Guide Featuring Fruit \& Vegetables (Produce for Better Health Foundation, n.d.). The training program consisted of two-3 hour training sessions given by Registered Dietitian/ Nutritionists (RDNs) with extensive store tour experience focusing on produce quality and pricing, and techniques for personalizing store tours for tourist groups. The student trainees then gave two-1 hour grocery store tours to student tourist volunteers recruited from large general education classes on campus. During each one-hour tour, the student trainee provided education to the volunteer tourist on fresh, dried, canned, and frozen produce. Tour topics included selecting, budgeting for, and incorporating produce into the diet, as well as the health benefits associated with produce consumption. The tour ended with the trainee and tourist sampling various fruits and vegetables.

\subsection{Participants, Sampling Procedures, and Sample Size}

The sample was a convenience sample. Twenty-five dietetics and nutrition students participated in the training program. The student participants consisted of those enrolled in a college level Community Nutrition class that was taken during the third year of study at a Midwestern university. These students were required to participate in the training as a class requirement. Additionally, the program was open to students who were in the fourth year of study and were interested in the training program.

\subsection{Measures and Covariates}

Student trainees completed a brief, three question survey at the beginning of the training asking them about their confidence in providing consumers with education about produce, whether they would consider retail dietetics as a future, and what expectations they had for the program. At the end of the program, the students completed a follow up survey with the same questions from the pre - training survey and additional questions related to evaluating the training program. Neither survey was pilot tested.

The primary outcome measures were changes in level of confidence in educating the public about produce and whether students would consider a career in retail dietetics. Secondary measures related to what students learned, what they thought was beneficial and what could be improved, as well as how conducive the grocery store was to the training.

Students rated their level of confidence in educating the public about produce and whether they would consider a career in retail dietetics using a 5-point Likert scale with response options ranging from "strongly disagree" to "strongly agree." Higher scores on the Likert response indicated more agreement with the statement. 


\subsection{Data Analysis}

Paired sample t-tests were used to analyze the difference between pre - and post - training scores on two measures, level of confidence in educating consumers about produce and whether students would consider giving more store tours in the future. Descriptive statistics were used to report data given in written responses.

\subsection{Limitations}

There are several limitations to this study. There were only 25 students who were trained as part of the grant program, 21 of which were required to do so as part of a class and 4 of which were volunteers. Therefore, the student sample is relatively small and is not a random sample of students. Additionally, only 2 measures of change were assessed, and there may be many additional variables impacting students' desires to give grocery store tours. Also, the student sample was relatively homogeneous, and while it may be representative of the state in which the program was conducted, it is likely not representative of the entire United States.

\section{Results}

Twenty-five student trainees completed the entire store tour training program. Twenty - one of the students (84\%) were third year students and four (16\%) of the students were forth year students. Twenty - two students (88\%) were female and three (12\%) were male. All students were white.

Table 1 highlights the changes in student confidence in discussing produce with clients and changes in whether students would consider giving grocery store tours as a future career path. With regards to changes in student confidence in educating consumers about produce, there was a significant difference between pre- and post-training values, $\mathrm{t}(24)=$ $2.831, \mathrm{p}=0.009$. However, with regards to whether students would consider giving grocery store tours as a future career path, there was no significant difference in pre- and post-training scores, $\mathrm{t}(24)=0.135, \mathrm{p}=0.894$.

Table 1. Mean confidence level in giving educating consumers on produce and interest in giving store tours as a career before and after training program.

\begin{tabular}{|c|c|c|}
\hline Question (n) & $\begin{array}{l}\text { Pre-training } \\
\text { score* } \\
\text { Mean (SD) }\end{array}$ & $\begin{array}{l}\text { Post - training } \\
\text { score* } \\
\text { Mean (SD) }\end{array}$ \\
\hline \multirow{2}{*}{$\begin{array}{l}\text { I feel confident about my ability to educate consumers on the health benefits of } \\
\text { fresh, frozen, and canned produce } \\
\text { I would consider grocery store dietetics as a future career path. }\end{array}$} & $3.800(0.577)$ & $4.320(0.802)$ \\
\hline & $3.640(0.995)$ & $3.680(1.145)$ \\
\hline \multicolumn{3}{|c|}{$\begin{array}{l}\text { *Responses were recorded on a } 5 \text { point Likert scale with " } 1=\text { strongly disagree", " } 2=\text { disagree", " } 3=\text { somewh } \\
\text { "4=agree", " } 5=\text { strongly agree" }\end{array}$} \\
\hline \multicolumn{3}{|l|}{$* *$ Significance at $\mathrm{p}<0.05$} \\
\hline \multicolumn{3}{|c|}{$\begin{array}{l}\text { Table } 2 \text { highlights what students felt they learned from the training program. Students indicated learning abo } \\
\text { different topics during the training. Forty percent of students }(10 / 25) \text { reported increasing their knowledge } \\
\text { benefits of produce, while } 24 \%(6 / 25) \text { were better able to compare the cost differences between fresh, frozen } \\
\text { and dried produce. Additionally, another } 20 \%(5 / 25) \text { stated a greater knowledge about storage and selection of } \\
\text { Many students indicated they learned how to interact with or communicate more effectively with clients. Twen } \\
\text { percent }(7 / 25) \text { were better able to adapt a store tour to meet the needs of their clients, while } 20 \%(5 / 25) \text { learn } \\
\text { explain things to clients, and } 12 \%(3 / 25) \text { gained experience interacting with clients conversationally. Finally, } \\
\text { felt they improved their presentation skills. }\end{array}$} \\
\hline \multicolumn{3}{|l|}{ Table 2. Student trainee responses to what they learned during training } \\
\hline What was learned & \multicolumn{2}{|c|}{ N (\%) of responses* } \\
\hline Benefits of produce & \multicolumn{2}{|c|}{$10(40)$} \\
\hline How to adapt a tour to meet the client's 1 & \multicolumn{2}{|c|}{$7(28)$} \\
\hline Comparing costs between different types of produce & \multicolumn{2}{|c|}{$6(24)$} \\
\hline Storage and selection of produce & \multicolumn{2}{|c|}{$5(20)$} \\
\hline How to explain things to clients & \multicolumn{2}{|c|}{$5(20)$} \\
\hline How to interact with clients conversationally & \multicolumn{2}{|c|}{3 (12) } \\
\hline Proper storage of fruits and vegetables & \multicolumn{2}{|c|}{$3(12)$} \\
\hline Comparing frozen and fresh produce & \multicolumn{2}{|c|}{$2(8)$} \\
\hline Improved presentation skills & \multicolumn{2}{|c|}{$2(8)$} \\
\hline How to select fresh produce & \\
\hline
\end{tabular}

*Only responses that were indicated by more than 1 student were included in the table.

\section{Discussion}

Dietitians are becoming more prevalent in retail venues. An important component of retail dietetics is communicating 
with the public. Grocery store tours are commonly used to teach healthy eating and shopping habits to consumers. To be effective, store tours must be targeted at meeting the nutritional and educational needs of those participating. The results of this study demonstrate that providing dietetics and nutrition students with training in giving effective grocery store tours increases their confidence in doing so and in working with the general public.

Improving confidence may lead students to have fewer reservations about giving tours when they become professionals, which may increase the frequency and proficiency with which the tours are given. Dietetics and nutrition students were significantly more confident in educating consumers about produce after the training than before the training. In a meta -analysis of students from the United States and the Republic of Korea, core self-confidence was shown to be an indicator of better academic performance (Stajkovic, Lee, Greenwald, \& Raffiee, 2015). This same study examined core confidence in sales associates in the motor vehicle industry and found that it was also associated with improved sales performance and job satisfaction (Stajkovic et al., 2015). This may indicate that, not only does confidence aid in academic performance, but it may also improve work performance and overall job satisfaction. These are important skills for students who will soon become young professionals.

Another study relating to confidence reported on 24 graduating medical students who participated in a 2 week surgery preparatory course which included three simulations (Bommer et al., 2017). In this study, some students were given an orientation to the simulation while others were not. Those who received the brief orientation experienced less anxiety, increased confidence, and had better performance in the simulations than those that did not receive it (Bommer et al., 2017). Additionally, Bommer et al. (2017) found that those who experienced more anxiety and less confidence during initial simulations continued to experience those same issues during later simulations. This may be another indicator that increasing students' confidence for a task will lead them to feel more prepared for that task.

Student trainees also stated they learned more about produce and communicating with the public during the store tour training sessions. While students certainly learn about produce selection, storage, and preparation during the formal dietetics and nutrition curriculum, opportunities to use the information may lead to better retention. Additionally, students use the information about produce in a practice setting, which provides them with application. Another critical learning experience for these students was communicating with clients spontaneously. Strong communication skills are not only critical in patient/ client care, they are also needed by employers. In 2013, Chegg, Inc. and Harris Interactive interviewed 2,001 $18-24$ year olds enrolled in two to four year U.S. colleges, and 1,000 hiring managers. They found that while students rated their own communication skills well, hiring managers did not agree (Chegg and Harris Interactive, 2013). While 54\% of students felt they were completely prepared to use public speaking on the job, only $43 \%$ of managers felt the same way. Additionally, $70 \%$ of students felt completely prepared to communicate with authority figures or clients, but only $44 \%$ of managers agreed (Chegg and Harris Interactive, 2013). This indicates that students need more experience with communication skills prior to entering the workforce. Studies of dietetics students in the UK, have shown that upper level dietetics students (fourth year) tend to have poorer attitudes about learning communication skills (Power \& Lennie, 2012). A training program where students must use communication skills in a practical setting may be of benefit.

Interestingly, students did not experience an increase in their desire to give tours. This may have occurred for several reasons. There were very few students in this course who had an interest in community health and working with the general public. Most of the students preferred to work in more clinical settings with individuals and other health care professionals. This may have created a limited interest for them in the training. Additionally, the student trainees were giving tours to other students who had volunteered to receive a tour for extra credit. Therefore, the students receiving the tour may have shown some disinterest in the process, which would have decreased the trainees' enthusiasm for giving the tour. Finally, some students experienced "no-shows" which were volunteers who did not attend their scheduled tour time. This left some trainees frustrated as they then had to give tours to other trainees or instructors in order to fulfill the course requirements.

In order to encourage more students to pursue retail dietetics and find it rewarding, store tour training programs may want to consider some of the following. First, having students give practice tours to community members interested in receiving the education may increase student's interest in the field. Having students give tours to small groups of community members instead of one tourist at a time may alleviate the frustration from "no-shows." Students may also prefer to have a slightly longer training period. Most of the students in this study only had 2 training sessions before giving tours, which may not have been sufficient. Finally, students would gain more practice and possibly more interest if they are able to give more than 2 practice tours during the training.

\section{Conclusion}

Retail dietetics is an emerging and growing field. While dietetics and nutrition students have the food and nutrition knowledge to apply in this setting, they lack the training of how to put this knowledge into practice. A training program 
designed to teach students how to give tours and that allows them experiences to give tours to customers or clients allows students to learn more about healthy foods, how to apply the knowledge, and how to communicate with future consumer, client, and patient populations. Future research should explore these relationships further, hopefully with a larger group of students. Additionally, a more diverse group of dietetics and nutrition students would certainly allow for further exploration of the impact of demographic variables.

\section{Acknowledgements}

The authors would like to acknowledge the two Registered Dietitians who gave their time to train the dietetics students in giving quality grocery store tours. We would also like to acknowledge the grocery stores participating in the store tour-training program. Finally, we would like to acknowledge the Produce for Better Health Foundation for grant funding for this project.

\section{References}

Baic, S., \& Thompson, J. L. (2007). Prevent It: using grocery store tours as an educational tool to promote heart health. ACSM's Health \& Fitness Journal, 11(1), 15-20. https://doi.org/10.1249/01.FIT.0000257707.07363.a0

Bommer, C., Sullivan, S., Campbell, K., Ahola, Z., Agarwal, S., O'Rourke, A., ... Liepert, A. E. (2017). Pre-simulation orientation for medical trainees: an approach to decrease anxiety and improve confidence and performance. The American Journal of Surgery. https://doi.org/10.1016/j.amjsurg.2017.09.038

Chegg and Harris Interactive. (2013). Bridge that gap: analyzing the student skill index. Retrieved from https://www.insidehighered.com/sites/default/server_files/files/Bridge That Gap-v8.pdf

Crawford, S. M., \& Kalina, L. (1993). The shop smart tour. Journal of Nutrition Education, 25(2), $100 \mathrm{~B}$. https://doi.org/10.1016/S0022-3182(12)80996-4

Food Marketing Institute. (2015). New survey: food retailers identified as wellness destination [Press release]. Retrieved from

http://www.fmi.org/news-room/news-archive/view/2015/03/10/new-survey-food-retailers-identified-as-wellness-d estination

Hilliard, E., Brunt, A., Stangl, C., \& Borr, M. (2016). Are Grocery Store Tours Capturing the Right Audience? Characteristics of Students Who Volunteer to Receive a Grocery Store Tour. Journal of Education and Training Studies, 4(9), 8. https://doi.org/10.11114/jets.v4i9.1720

Milliron, B. J., Woolf, K., \& Appelhans, B. M. (2012). A point-of-purchase intervention featuring in-person supermarket education affects healthful food purchases. Journal of Nutrition Education and Behavior, 44(3), 225-232. https://doi.org/10.1016/j.jneb.2011.05.016

Nikolaus, C. J., Muzaffar, H., \& Nickols-Richardson, S. M. (2016). Grocery Store (or Supermarket) Tours as an Effective Nutrition Education Medium: A Systematic Review. Journal of Nutrition Education and Behavior, 48(8), 544-554.e541. https://doi.org/10.1016/j.jneb.2016.05.016

Power, B. T., \& Lennie, S. C. (2012). Pre-registration dietetic students' attitudes to learning communication skills. Journal of Human Nutrition and Dietetics, 25(2), 189-197. https://doi.org/10.1111/j.1365-277X.2012.01226.x

Produce for Better Health Foundation, F. A. V. M. M. (n.d.). Grocery store tour training guide featuring fruit \& vegetables for nutrition $\&$ dietetics students.

Stajkovic, A. D., Lee, D., Greenwald, J. M., \& Raffiee, J. (2015). The role of trait core confidence higher-order construct in self-regulation of performance and attitudes: Evidence from four studies. Organizational Behavior and Human Decision Processes, 128(Supplement C), 29-48. https://doi.org/10.1016/j.obhdp.2015.02.001

Thompson, K. L., Silver, C., Pivonka, E., Gutschall, M., \& McAnulty, L. (2015). Fruit-and vegetable-focused grocery store tour training kit to promote peer-on-peer nutrition education utilizing nutrition and dietetics students. Journal of Nutrition Education and Behavior, 47(5), 472-476.e471. https://doi.org/10.1016/j.jneb.2015.04.329

\section{Copyrights}

Copyright for this article is retained by the author(s), with first publication rights granted to the journal.

This is an open-access article distributed under the terms and conditions of the Creative Commons Attribution license which permits unrestricted use, distribution, and reproduction in any medium, provided the original work is properly cited. 